\title{
Stability of solar correction for calculating ionospheric trends
}

\author{
Jan Laštovička, Dalia Burešová, Daniel Kouba, and Peter Križan \\ Institute of Atmospheric Physics, Bocni II, 14131 Prague, Czech Republic \\ Correspondence to: Jan Laštovička (jla@ufa.cas.cz)
}

Received: 21 October 2016 - Revised: 24 November 2016 - Accepted: 28 November 2016 - Published: 16 December 2016

\begin{abstract}
Global climate change affects the whole atmosphere, including the thermosphere and ionosphere. Calculations of long-term trends in the ionosphere are critically dependent on solar activity (solar cycle) correction of ionospheric input data. The standard technique is to establish an experimental model via calculating the dependence of ionospheric parameter on solar activity from the whole analysed data set, subtract these model data from observed data and analyse the trend of residuals. However, if the solar activity dependence changes with time, the solar correction calculated from the whole data set may result in miscalculating the ionospheric trends. To test this, data from two European ionospheric stations - Juliusruh and Slough/Chilton - which provide long-term reliable data, have been used for the period 1975-2014. The main result of this study is the finding that the solar activity correction used in calculating ionospheric long-term trends need not be stable, as was assumed in all previous investigations of ionospheric trends. During the previous solar cycle 23 and the current solar cycle 24, the solar activity correction appears to be different from that for the previous period and the Sun seems to behave in a different way than throughout the whole previous era of ionospheric measurements. In future ionospheric trend investigations the non-stability of solar activity correction has to be very seriously taken into account, because it can substantially affect calculated long-term trends of ionospheric parameters.
\end{abstract}

Keywords. Ionosphere (mid-latitude ionosphere)

\section{Introduction}

The global climate change caused by the increasing concentration of radiatively active greenhouse gases affects not only the troposphere; it affects also the upper atmosphere, including the thermosphere and ionosphere, where it evokes longterm trends (e.g. Laštovička et al., 2012). However, to cal- culate the trends, the effect of the 11-year solar cycle must be removed from the data or at least very suppressed, as it is much stronger than the long-term trend, particularly for ionospheric quantities. Usually this is done by calculating the model of solar activity effect on the data from data themselves; after subtracting the solar contribution from the observed data the long-term trend is calculated from residuals. Another possibility is for example the multiple linear regression with simultaneous inclusion of solar activity and time, or some more sophisticated methods. Both these approaches are applied here and provide similar results. As Cnossen and Frantzke (2014) showed, the long-term trends of $f o \mathrm{~F} 2$ and $h m \mathrm{~F} 2$ (critical frequency of ionospheric F2 region and its peak height, respectively) are highly linear, so the linear approximation is sufficient, and the same can be expected for corresponding parameters of the ionospheric $\mathrm{E}$ region, $f o \mathrm{E}$ and $h m \mathrm{E}$. The solar activity effect has usually been removed or suppressed using solar activity proxies, particularly F10.7 (sunspot number is the worse option; see e.g. Mielich and Bremer, 2013), because decades-long homogeneous series of solar extreme ultraviolet (EUV) data are not available.

The last extremely long and deep solar minimum, particularly years 2008 and 2009, might create some problems in calculating long-term trends, because F10.7 is most probably unable to describe the large decrease of solar EUV flux in these years (e.g. Laštovička, 2013, and references therein; Solomon et al., 2010). The thermospheric density was anomalously low in 2008-2009, remarkably lower than that expected from F10.7 (e.g. Solomon et al., 2010). A similar problem was found for ionospheric parameters $h \mathrm{mF} 2$ (e.g. Roininen et al., 2015) and foF2 (e.g. Laštovička, 2013). Danilov and Konstantinova (2016) found some distortion of trends in $f o \mathrm{~F} 2$ in these years; however, more recently the trend recovered back to the expected "trajectory". Therefore, the original objective of this study was to examine whether 
trends in the E region are distorted by this extreme solar minimum.

However, during this examination a more serious problem was detected, namely the possibility of change of the solar activity correction necessary for trend investigations during the examined period. Also Elias et al. (2014), when studying long-term trends in $f_{o} \mathrm{~F} 2$, found some changes of trends during solar cycle 23, including the deep minimum $23 / 24$, which they tentatively attributed to changes in the solar EUV-F10.7 relationship. Moreover the Sun seems to change its behaviour. Balogh et al. (2014; their Fig. 4) observed an evident change of relationship between sunspot number and F10.7 and a remarkable decrease of the sunspot formation fraction parameter during solar cycle 23 and early solar cycle 24 . Therefore, the objective of this article was changed to investigating the temporal stability of solar activity correction in investigating ionospheric trends.

Section 2 describes data and methods used. Section 3, the main part of the paper, contains the results and discussion. The results are summarized in Conclusions (Sect. 4).

\section{Data and methods}

Since the long period 1975-2014 is investigated, highquality, continuous and long data series are needed. Therefore, two European midlatitude ionospheric stations are selected - Slough/Chilton $\left(51.5^{\circ} \mathrm{N}, 1.3^{\circ} \mathrm{W}\right.$; geomagnetic latitude $\left.53.6^{\circ} \mathrm{N}\right)$ and Juliusruh $\left(54.6^{\circ} \mathrm{N}, 13.4^{\circ} \mathrm{W}\right.$; geomagnetic latitude $54^{\circ} \mathrm{N}$ ) - which provide the best historical ionospheric data in Europe (Burešová, 1997). Historical data are taken from the Rutherford Appleton Laboratory database (http://www.ukssdc.ac.uk/wdcc1/iono_menu.html), more recent data from the SPIDR database (http: //spidr.ionosonde.net/spidr), and a few most recent months from the digisonde database GIRO (http://giro.uml.edu/). Basic data $f o \mathrm{E}$, monthly noontime medians calculated from daily medians at 10-14 local time (LT), are averaged to obtain yearly noontime mean values. To consider solar activity, parameter F10.7 is used (ftp://ftp.ngdc.noaa.gov/ STP/space-weather/solar-data/solar-features/solar-radio/ noontime-flux/penticton/penticton_observed/tables/). Also the composite solar Lyman-alpha flux $(\mathrm{F} \alpha)$, taken from http://lasp.colorado.edu/lisird/lya/, is applied since there is a very close correlation between variations of solar Lymanalpha and Lyman-beta fluxes, the latter being one of the principal ionizing agents of the $\mathrm{E}$ region. The geomagnetic activity index Ap was used as well. The impact of Ap on yearly values of $f o \mathrm{E}$ was found to be quite negligible, and it is not considered further, as was the case in $f o \mathrm{~F} 2$ solar corrections (e.g. Laštovička et al., 2006; Perrone and Mikhailov, 2016). foF 2 from Slough/Chilton is used in the same way as $f o \mathrm{E}$ to check the impact of changing solar correction on $f o \mathrm{~F} 2$ trend calculations.
Table 1. Percentage of total variance of yearly values of $f_{o} \mathrm{E}$ accounted for by solar activity proxies (Eq. 1) for the whole period and for three sub-periods, for Juliusruh and Chilton (values separated with a slash).

\begin{tabular}{lll}
\hline & F10.7 & F $\alpha$ \\
\hline $1975-2014$ & $0.88 / 0.91$ & $0.89 / 0.92$ \\
$1975-1990$ & $0.96 / 0.91$ & $0.93 / 0.92$ \\
$1990-2005$ & $0.94 / 0.98$ & $0.93 / 0.95$ \\
$2006-2014$ & $0.78 / 0.95$ & $0.85 / 0.94$ \\
\hline
\end{tabular}

Trends are calculated in two ways mentioned previously in the Introduction. First the observational model of dependence of ionospheric parameter on solar activity is calculated using both F10.7 and F $\alpha$. The results are very similar (although not identical), because correlation of yearly values of these solar parameters is very close, $r=0.98$. Then the model values are subtracted from observational values, and residuals are used to estimate trends. The percentage of total variance explained by solar proxies is calculated as well. The other approach used is to calculate trends by the multiple linear regression with simultaneous application of a solar proxy and time as a proxy for linear trend.

\section{Results and discussion}

Let us begin with calculation of the observational model of linear dependence of $f o \mathrm{E}$ on solar activity by the least square fitting using separately either F10.7 or F $\alpha$ :

$f o \mathrm{E}=A+B \cdot$ solar.

Table 1 (first row) shows the percentage of total variance of $f o$ E explained by Eq. (1) for Juliusruh and Chilton when the solar dependence is calculated over the whole interval 19752014. Solar activity explains about $90 \%$ of the total variance of $f o \mathrm{E}$, which means a clear solar dominance. Both solar proxies provide practically the same results.

The next step is to subtract the model values from observed values and then estimate the trend from the residuals. Figure 1 shows the behaviour of the residuals $\Delta f o \mathrm{E}=f o \mathrm{E}-f o \mathrm{E}_{\text {model }}$. The evolution of $\Delta f o \mathrm{E}$ does not look very plausible, particularly in its most recent years, and it does not enable a trend to be estimated. Moreover, Bremer and Peters (2008) found some dependence of $f o \mathrm{E}$ trends on stratospheric ozone trends, which is supported by model results of Akmaev et al. (2006) showing a peak of the stratospheric ozone depletion effect on the neutral atmospheric density not in the stratosphere but at a height of $110 \mathrm{~km}$ at the peak of $\mathrm{E}$ layer. This would mean a change of trend of $f o \mathrm{E}$ in mid-1990 together with the change of total ozone trend at northern middle latitudes (e.g. Harris et al., 2008), which is not seen in Fig. 1. Observationally we can divide the whole period into three parts: 1975-1990, a decrease of 


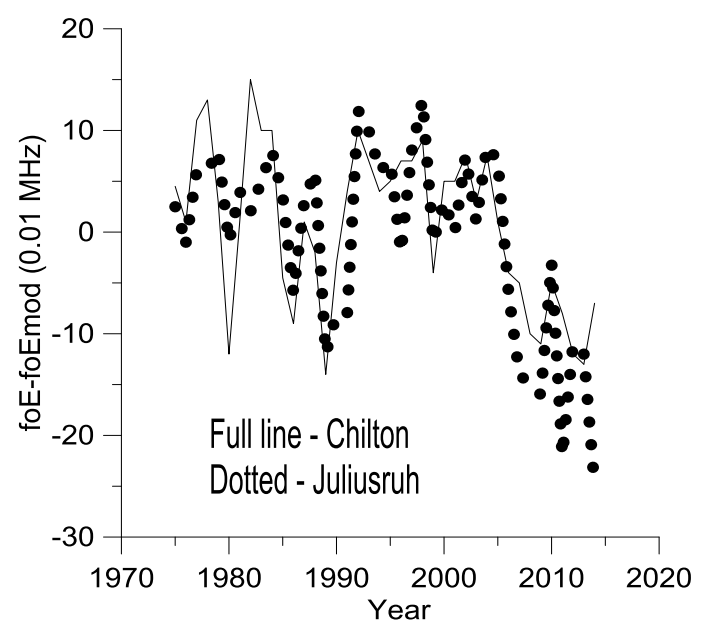

Figure 1. Residuals $\Delta f o \mathrm{E}(0.01 \mathrm{MHz})$ after removal of solar activity (F10.7) influence (Eq. 1), yearly values, for Chilton (full line) and Juliusruh (dotted line).

$\Delta f o \mathrm{E} ; 1990-2005$, stagnation or a mini-increase after jumpup; 2006-2014, rapid decrease. Whereas in the first two subperiods residuals vary within $\pm 0.1 \mathrm{MHz}$, in the third subperiod they fall to remarkably lower negative values. Originally the third interval was 2005-2014, but 2005 was a large outlier in residuals. Therefore, it remained only in 19902005, where it fits well.

Now the whole procedure, calculating the observational model with Eq. (1), then subtracting model values from observations and constructing the time development of residuals, is repeated separately for all three sub-intervals. Table 1 reveals an evident increase of percentage of total variance of foE explained by solar activity, on average about $93-94 \%$, except for Juliusruh, 2006-2014, when some oscillations appear (Fig. 2). Table 2 shows that solar coefficients $B$ from Eq. (1) for the whole interval and for the three sub-intervals somewhat differ, although not much. The coefficients $B$ in individual sub-intervals have been becoming smaller in recent years. This timing is in accord with the changes in solar activity mentioned in Introduction, which began during solar cycle 23.

The differences between solar coefficients $B$ in different sub-intervals are relatively small, but their impact on time evolution of $\Delta f o \mathrm{E}$ is substantial (Fig. 2). Figure 2 shows the behaviour of residuals after application of solar corrections separately in individual sub-intervals. The pattern is quite different from that depicted in Fig. 1; it is clear and physically plausible. In the beginning there is a slight negative trend, which turns into no trend in the mid-1990s in parallel with the change (levelling off or reversal) of trend in ozone at northern middle latitudes (Harris et al., 2008). The slight negative trend means a change by $0.05-0.06 \mathrm{MHz}$ over $1975-$ 1995 , i.e. trend of about $-0.03(-0.025) \mathrm{MHz}_{\text {decade }}{ }^{-1}$ for both stations.



Figure 2. Residuals $\Delta f o \mathrm{E}(0.01 \mathrm{MHz})$ after removal of solar activity (F10.7) influence (Eq. 1) separately for the three sub-periods 19751990, 1990-2005, and 2005-2006, yearly values, for Chilton (full line) and Juliusruh (dashed line).

Bremer (2008) analysed the trends in foE using data of 71 ionosondes located over the world. He received a weak but statistically significant average trend of $+0.013 \pm$ $0.005 \mathrm{MHz}$ decade ${ }^{-1}$, but the histogram of trends used covers a range from -0.04 to $+0.07 \mathrm{MHz}$ decade $^{-1}$. Thus our trends for Slough/Chilton and Juliusruh are within the range of trends found by Bremer (2008). Moreover, Troms $\varnothing$ in northern Norway also provides a negative trend in $f o \mathrm{E}$ (Hall et al., 2007). Thus it looks like northern Europe is a region of negative trends in $f o \mathrm{E}$.

The other approach used is to calculate trends by the multiple linear regression:

$f o \mathrm{E}=A+B \cdot$ solar $+C \cdot$ time.

Table 3 presents the percentage of total variance of yearly values of $f o \mathrm{E}$ accounted for by solar activity proxies and trend (Eq. 2) for the whole period and for three sub-periods, for Juliusruh and Chilton. It is evident that dividing the solar activity correction into three sub-periods increased the percentage of total variance described by solar activity variability and trend to 95 and $96 \%$ for Juliusruh and Chilton except for Juliusruh, 2006-2014, where Figs. 1 and 2 display larger random-like variability.

Trend coefficients for Juliusruh and Chilton are shown for the whole dataset in Table 4 (sub-periods are too short to provide reliable trend coefficients). These trend coefficients for Chilton provide a decrease of $f o \mathrm{E}$ over the analysed 40year period to be $0.04-0.08 \mathrm{MHz}$, which agrees with estimate from Fig. 2, 0.05-0.06 MHz, but the latter decrease is realized in the first half of the studied period only. However, the Chilton trend coefficients from Table 4 are statistically insignificant. Trend coefficients given in Table 4 for Julius- 
Table 2. Solar coefficient $B$ from Eq. (1) for yearly values of $f o E$ for the whole period and for three sub-periods, for Juliusruh and Chilton (values separated with a slash).

\begin{tabular}{lll}
\hline & F10.7 & $\mathrm{F} \alpha$ \\
\hline $1975-2014$ & $0.0053 \pm 0.0003 / 0.0053 \pm 0.0003$ & $0.34 \pm 0.02 / 0.35 \pm 0.02$ \\
$1975-1990$ & $0.0050 \pm 0.0003 / 0.0050 \pm 0.0004$ & $0.33 \pm 0.02 / 0.33 \pm 0.03$ \\
$1990-2005$ & $0.0045 \pm 0.0003 / 0.0050 \pm 0.0002$ & $0.29 \pm 0.02 / 0.32 \pm 0.02$ \\
$2006-2014$ & $0.0038 \pm 0.0011 / 0.0047 \pm 0.0006$ & $0.25 \pm 0.06 / 0.30 \pm 0.04$ \\
\hline
\end{tabular}

Table 3. Percentage of total variance of yearly values of $f o \mathrm{E}$ accounted for by solar activity proxies and trend (Eq. 2) for the whole period and for three sub-periods, for Juliusruh and Chilton (values separated with a slash).

\begin{tabular}{lll}
\hline & F10.7 & F $\alpha$ \\
\hline $1975-2014$ & $0.92 / 0.94$ & $0.91 / 0.94$ \\
$1975-1990$ & $0.97 / 0.96$ & $0.95 / 0.96$ \\
$1990-2005$ & $0.95 / 0.98$ & $0.93 / 0.95$ \\
$2006-2014$ & $0.78 / 0.96$ & $0.85 / 0.96$ \\
\hline
\end{tabular}

Table 4. Trends (MHz/decade) of $f o E$ calculated from Eq. (2), for Juliusruh and Chilton (values separated with a slash).

\begin{tabular}{lll}
\hline & $\mathrm{F} 10.7$ & $\mathrm{~F} \alpha$ \\
\hline $1975-2014$ & $-0.03 /-0.01$ & $-0.04 /-0.02$ \\
\hline
\end{tabular}

ruh provide a larger trend, which contradicts the change of Juliusruh $f o \mathrm{E}$ (Fig. 2). However, trends derived from Juliusruh data are less reliable due to the significantly larger scatter of Juliusruh values in the third sub-period, as illustrated by both Figs. 1 and 2.

Figure 2 indicates that it would be correct to apply the piecewise linear trend approach. There is a trend of $f o \mathrm{E}$ in the first part of the examined period and no trend in the second part. Trends calculated via approach with Eq. (1) over the period 1975-1996 with solar proxy F10.7 provide trends for Chilton of $-0.011 \pm 0.008(\sigma)$ and for Juliusruh of $-0.019 \pm 0.005 \mathrm{MHz}$ decade ${ }^{-1}$. The trend is more significant for Juliusruh (at more than $3 \sigma$ level), because Juliusruh values evolve in a smoother way over 1975-1996 than Chilton values. These trend coefficients provide a decrease of $f o \mathrm{E}$ from 1975 to 1996 by $0.025 \mathrm{MHz}$ for Chilton and $0.041 \mathrm{MHz}$ for Juliusruh, which is somewhat less than estimates from Fig. $2(0.05-0.06 \mathrm{MHz})$.

Table 2 shows values of solar coefficients $B$ from Eq. (1). They all are statistically quite significant, which is not surprising because the percentage of total variance of $f o \mathrm{E}$ accounted for by solar activity variability is around $90 \%$ and more (Table 1). It is interesting that such relatively mild changes of solar activity correction (particularly for Chilton) can quite change the pattern of $f o$ E residuals, changing Fig. 1
Table 5. Percentage of total variance of yearly values of $f o \mathrm{~F} 2$ accounted for by F10.7 (Eq. 1) for the whole period and for three sub-periods for Chilton.

\begin{tabular}{ll}
\hline & F10.7 \\
\hline $1975-2014$ & 0.97 \\
$1975-1990$ & 0.99 \\
$1990-2005$ & 0.95 \\
$2006-2014$ & 0.98 \\
\hline
\end{tabular}

into Fig. 2. The solar coefficients are somewhat (although not much) decreasing with time. Such systematic change seems to be of solar origin. For example, when we look at the behaviour of the sunspot formation fraction parameter (Balogh et al., 2014; their Fig. 4), it evidently begins to decrease in the late 1990s and it is decreasing continuously until 2010 (end of the data series). Thus the period 1975-1990 is not impacted by this solar behaviour change, the period 1990-2005 is affected partly and the period 2005-2014 seems to be fully affected, which coincides with changes of solar coefficient in Table 2. On the other hand, changes of $f o$ E sensitivity to solar activity are similar for F10.7 and F $\alpha$ (proxy of solar EUV flux versus spectral line from the soft end of EUV range). So it may be that there are also some changes of ionospheric sensitivity, although it is difficult to say what their physical origin could be. First of all, solar physics should answer the question of what is happening with the Sun.

In the case that our study were limited only to the period 1975-2005, then Fig. 1 would indicate a slight positive tendency (if any, rather none) for Juliusruh, whereas Fig. 2 would indicate a slight negative tendency. This illustrates how important it is to check/test and consider non-stability of solar correction in long-term ionospheric trend studies.

The stability of solar correction has been examined above only for $f o$ E. Let us now look at $f o$ F2. Chilton and Juliusruh data provide quite similar results. Therefore only those for Chilton are presented. An approach based on Eq. (1) applied to $f o \mathrm{~F} 2$ is used. Table 5 shows that almost all variance (95$99 \%$ ) of $f o \mathrm{~F} 2$ is accounted for by solar activity variability. However, even in such a situation there are some changes of solar correction in individual sub-periods with some impact on $f o \mathrm{~F} 2$ residuals. Figure 3 shows evolution of $f o \mathrm{~F} 2$ when only one solar correction is applied for the whole period, 


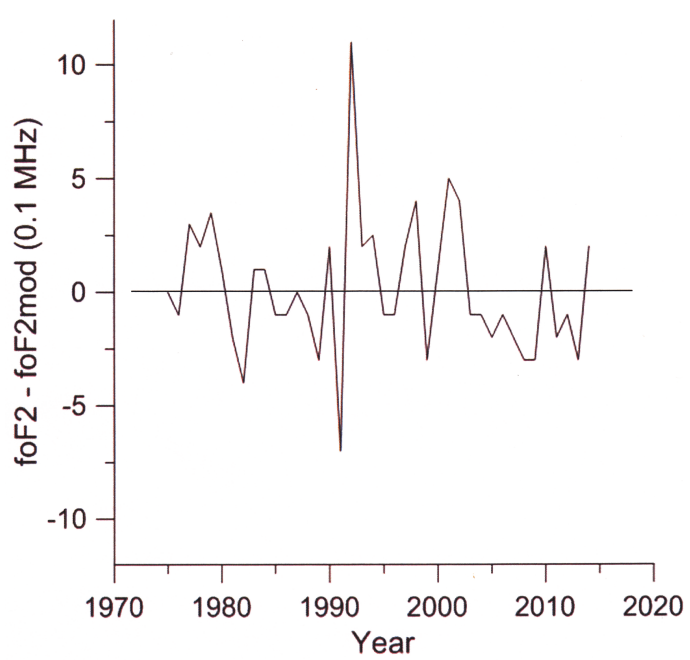

Figure 3. Residuals $\Delta f o \mathrm{~F} 2(0.1 \mathrm{MHz})$ after removal of solar activity (F10.7) influence (Eq. 1), yearly values, for Chilton. Thin horizontal line - reference (zero) level.

whereas Fig. 4 shows behaviour of residuals after application of three different solar corrections in three sub-intervals. Whereas Fig. 3 perhaps indicates some slight insignificant negative trend of $f o \mathrm{~F} 2$, Fig. 4 clearly displays no trend. Thus there is some (slight) impact of changes of solar correction on evolution of $f o \mathrm{~F} 2$ residuals. Figure 4 also displays no effect of change of ozone trends in the mid-1990s on trends in $f o \mathrm{~F} 2$. Unfortunately, the pattern of $f o \mathrm{~F} 2$ residuals in Figs. 3 and 4 is "poisoned" by two outliers in 1991 and 1992, which largely compensate each other, so they do not affect trend. However, they affect scatter of data and therefore slightly lower the value of percentage in Table 5 for the period 1990-2005.

\section{Conclusions}

Data of two European ionospheric stations - Juliusruh and Chilton - which provide long-term reliable data, have been used for the period 1975-2014. The main result of this study is the finding that the solar activity correction used in calculating ionospheric long-term trends need not be stable, as was assumed in all previous investigations of ionospheric trends. During the previous solar cycle 23 and the current solar cycle 24 , the solar activity correction appears to be different from that for the previous period and the Sun seems to behave in a different way than throughout the whole previous era of ionospheric measurements. Whether it is related to the generally low level of solar activity in the 21st century compared to the second half of the 20th century remains an open question. Anyway, in future ionospheric trend investigations the non-stability of solar activity correction has to be very seriously taken into account, because it can substantially affect long-term evolution and calculated trends of ionospheric parameters (compare Figs. 1 and 2).

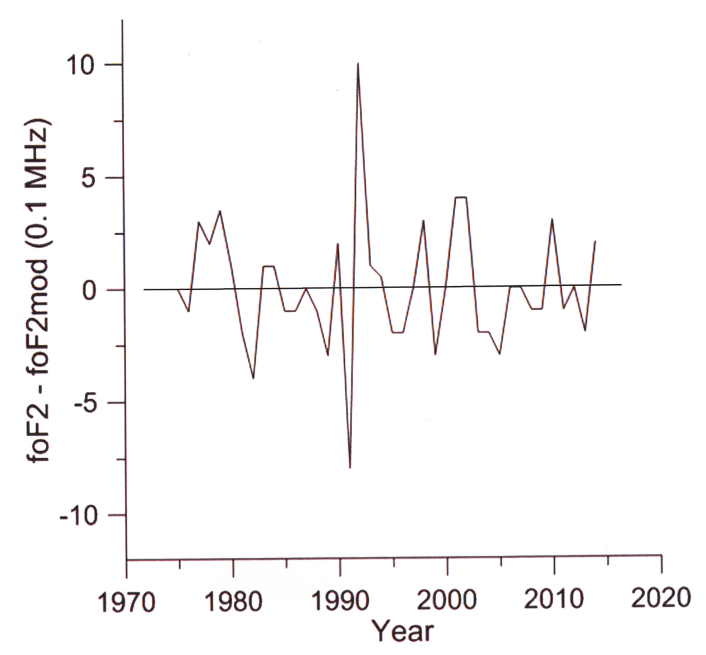

Figure 4. Residuals $\Delta f o \mathrm{~F} 2(0.1 \mathrm{MHz})$ after removal of solar activity (F10.7) influence (Eq. 1) separately for the three sub-periods 19751990, 1990-2005, and 2005-2006, yearly values, for Chilton. Thin horizontal line - reference (zero) level.

\section{Data availability}

Ionospheric data are available at the Rutherford Appleton Laboratory database (http://www.ukssdc.ac.uk/wdec1/ iono_menu.html), SPIDR database (http://spidr.ionosonde. net/spidr), and the digisonde database GIRO (http://giro.uml. $\mathrm{edu} /$ ), and solar Lyman-alpha data at http://lasp.colorado. edu/lisird/lya/.

Author contributions. Jan Laštovička did most of the work, Dalia Burešová and Daniel Kouba helped with data mining, and Peter Križan helped with data evaluation.

Competing interests. The authors declare that they have no conflict of interest.

Acknowledgements. Support by the Grant Agency of the Czech Republic via Grant 15-03909S is acknowledged.

The topical editor, K. Hosokawa, thanks A. G. Elias and one anonymous referee for help in evaluating this paper. 


\section{References}

Akmaev, R. A., Fomichev, V. I., and Zhu, X.: Impact of middleatmospheric composition changes on greenhouse cooling in the upper atmosphere, J. Atmos. Sol.-Terr. Phy. 68, 1879-1889, doi:10.1016/j.jastp.2006.03.008, 2006.

Balogh, A., Hudson, H. S., Petrovay, K., and von Steiger, R.: Introduction to the solar activity cycle: Overview of causes and consequences, Space Sci. Rev., 186, 1-15, doi:10.1007/s11214014-0125-8, 2014.

Bremer, J.: Long-term trends in the ionospheric E and F1 regions, Ann. Geophys., 26, 1189-1197, doi:10.5194/angeo-261189-2008, 2008.

Bremer, J. and Peters, D.: Influence of stratospheric ozone changes on long-term trends in the mesosphere and lower thermosphere, J. Atmos. Sol.-Terr. Phy., 70, 1473-1481, doi:10.1016/j.jastp.2008.03.024, 2008.

Burešová, D.: Results of $f o \mathrm{~F} 2$ data testing with the UNDIV program, Studia Geoph. Geod., 41, 82-87, doi:10.1023/A:1023392808566, 1997.

Cnossen, I. and Franzke, C.: The role of the Sun in long-term change in the F2 106 peak ionosphere: new insights from EEMD and numerical modelling, J. Geophys. Res.-Space, 119, 86108623, doi:10.1002/2014JA020048, 2014.

Danilov, A. D. and Konstantinova, A. V.: Trends in the critical frequency of F2 layer after 2009, Geomagn. Aeron., 56, 302-310, doi:10.1134/S0016793216030026, 2016.

Elias, A., de Haro Barbas, B. F., Shibasaki, K., and Souza, J. R.: Effect of solar cycle 23 in $f o F 2$ trend estimation, Earth Planet. Space, 66, 111, doi:10.1186/1880-5981-66-111, 2014.

Hall, C. M., Brekke, A., and Cannon, P. S.: Climatic trends in Eregion critical frequency and virtual height above Troms $\varnothing\left(70^{\circ} \mathrm{N}\right.$, $\left.10^{\circ} \mathrm{E}\right)$, Ann. Geophys., 25, 2351-2357, doi:10.5194/angeo-252351-2007, 2007.
Harris, N. R. P., Kyrö, E., Staehelin, J., Brunner, D., Andersen, S.B., Godin-Beekmann, S., Dhomse, S., Hadjinicolaou, P., Hansen, G., Isaksen, I., Jrrar, A., Karpetchko, A., Kivi, R., Knudsen, B., Krizan, P., Lastovicka, J., Maeder, J., Orsolini, Y., Pyle, J. A., Rex, M., Vanicek, K., Weber, M., Wohltmann, I., Zanis, P., and Zerefos, C.: Ozone trends at northern mid- and high latitudes - a European perspective, Ann. Geophys., 26, 1207-1220, doi:10.5194/angeo-26-1207-2008, 2008.

Laštovička, J.: Are trends in total electron content (TEC) really positive?, J. Geophys. Res.-Space, 118, 3831-3835, doi:10.1002/jgra.50261, 2013.

Laštovička, J., Mikhailov, A. V., Ulich, T., Bremer, J., Elias, A. G., Ortiz de Adler, N., Jara, V., Abarca del Rio, R., Foppiano, A. J., Ovalle, E., and Danilov, A. D.: Long-term trends in foF2: A comparison of various methods, J. Atmos. Sol.-Terr. Phy., 68, 1854-1870, doi:10.1016/j.jastp.2006.02.009, 2006.

Laštovička, J., Solomon, S. C., and Qian, L.: Trends in the neutral and ionized 122 upper atmosphere, Space Sci. Rev., 168, 113145, doi:10.1007/s11214-011-9799-3, 2012.

Mielich, J. and Bremer, J.: Long-term trends in the ionospheric F2 region with different solar activity indices, Ann. Geophys., 31, 291-303, doi:10.5194/angeo-31-291-2013, 2013.

Perrone, L. and Mikhailov, A. V.: Geomagnetic control of the midlatitude $f o \mathrm{~F} 1$ and $f o \mathrm{~F} 2$ long-term variations: Recent observations in Europe, J. Geophys. Res.-Space, 121, 7185-7192, doi:10.1002/2016JA022715, 2016.

Roininen, L., Laine, M., and Ulich, T.: Time-varuing ionosonde trend: Case study of Sodankyla $h m \mathrm{~F} 2$ data 1957-2014, J. Geophys. Res.-Space Phys., 120, 6851-6859, doi:10.1002/2015JA021176, 2015.

Solomon, S. C., Woods, T. N., Didkovski, L. V., Emmert, J. T., and Qian, L.: Anomalously low solar extreme-ultraviolet irradiance and thermospheric density during solar minimum, Geophys. Res. Lett., 37, L16103, doi:10.1029/2010GL044468, 2010. 